\title{
“SALVE CORREIA DEFREITAS!": SOCIEDADE E POLÍTICA NO BRASIL ENTRE 1850-1932 ATRAVÉS DA TRAJETÓRIA DE UM PARANAENSE ${ }^{1}$
}

\author{
Ana Crhistina Vanali ${ }^{2}$
}

\footnotetext{
- Enviado em 31/12/2015
}

- Aprovado em 08/03/2016

O objeto de pesquisa é o estudo da trajetória social de Manoel Correia de Freitas (18511932), político paranaense que, entre o final do século XIX e início do século XX, teve forte inserção na política paranaense e nacional difundindo as ideias republicanas e influenciando na fundação de clubes republicanos e dos partidos republicanos no Paraná e em outros estados brasileiros. O objetivo principal é investigar, sociologicamente, o modo como esse político percorreu o espaço social de seu tempo. Sendo assim, o problema de pesquisa será analisar as seguintes questões: como se deu a trajetória social de Manoel Correia de Freitas? Quais os aspectos de sua trajetória social que lhe deram destaque e fizeram com que se tornasse uma influência na política estadual e nacional no final do século XIX e início do século XX? Dada à inexistência de uma biografia de Manoel Correia de Freitas, à construção do trabalho será feita com dados primários recolhidos em pesquisas documentais em diversas instituições do Brasil e do exterior.

A crise do regime monárquico brasileiro veio acompanhada do surgimento e da expansão do movimento republicano no final do século XIX. Nesse período a imprensa não somente se colocou como palco dos debates institucionais, como também teve papel de poder informal. Recuperando nos periódicos nacionais e internacionais da época de atuação de Manoel Correia, teremos o modelo de república proposto por ele que circulava nesses materiais, recompondo as configurações sociais e

\footnotetext{
${ }^{1}$ Pesquisa de doutorado em andamento sob a orientação do Professor Doutor Ricardo Costa de Oliveira no Programa de Pós-graduação em Sociologia da UFPR.
}

${ }^{2}$ Doutoranda em Sociologia pela Universidade Federal do Paraná. Endereço eletrônico: anacvanali@yahoo.com.br 
seu habitus para aprender seus ideários republicanos e compreender as redes e configurações que ensejaram a produção e difusão de tais ideários. O estudo da sua biografia vai permitir a compreensão dos variados posicionamentos políticos nas redes que influenciaram o republicanismo no Paraná e no Brasil que, em sua vertente dominante, estava vinculado ao projeto de modernização do país conduzida pelas elites detentoras de capital econômico e político que permitiu o controle da implantação da república no Paraná e no Brasil.

Uma vez os dados levantados, a relevância teórica do trabalho consiste na compreensão da relação entre os conceitos de indivíduo e sociedade, na convergência entre as perspectivas teóricas de Pierre Bourdieu e Norbert Elias acerca dos estudos biográficos da Sociologia. O estudo da trajetória de Manoel Correia de Freitas pode contribuir para o entendimento dos fatores sociais que propiciaram a realização de uma biografia capaz de influenciar gerações posteriores e do processo de reatualização do habitus na trajetória de um indivíduo, uma vez que o político transitou por diferentes campos no espaço social.

Manoel Correia nasceu em Paranaguá, em 29 de maio de 1851 e faleceu em Curitiba, em 23 de junho de 1932. Foi jornalista e propagandista do regime republicano. Esteve profundamente vinculado ao meio político paranaense, foi deputado estadual na legislatura de 1908-1909 e deputado federal nas legislaturas de 1909-1911 e de 1912-1914 (pouco tempo como representante político se comparada a sua atuação dentro do campo político para a implantação da república). Apesar de ficar pouco tempo como político eleito, foi justamente porque detinha um montante considerável de capital e apresentava uma trajetória estruturada por relações de poder e de mando no Estado que sempre foi fonte de consulta para os outros políticos.

Aos sete anos foi para a escola primária e depois disso nada consta sobre o seu processo de educação formal. Foi essencialmente um autoditada. Filho do Capitão Domingos Correia de Freitas, natural de São Francisco, e de Dona Josepha Leite Bastos Freitas, de família tradicional parnanguara. Maiores indicações sobre a ocupação dos pais não foram encontradas, mas a caracterização do pai como 'homem do mar' e a notícia da libertação dos escravos de sua família na mesma ocasião de Vicente Machado permitem posicioná-lo ao menos entre os setores médios em ascensão. Seu capital de relações familiares foi determinante para a boa inserção que teve no campo político catarinense, pois tanto seu pai quanto seu irmão José Correia de Freitas (que também foi um político de importância no período) nasceram em Santa Catarina. A historiografia destaca que aos 15 anos de idade já empreendia campanha abolicionista e republicana. Em 1872 participou da fundação do Clube Literário de Paranaguá e em 1881 fundou em Curitiba, junto com Rocha Pombo, um periódico republicano intitulado A Verdade. Mais tarde colaborou no Livre Paraná de Fernando 
Simas, periódico também abolicionista e republicano. No final dos anos 1880 Manoel Correia iniciou sua 'peregrinação', viajando por todo o país para difundir a doutrina republicana, participando de encontros, fazendo conferências e representando o Paraná e (ou) Santa Catarina em congressos republicanos no Rio de Janeiro e em São Paulo. Envolveu-se, pois, com todos os tipos de ações políticas e culturais existentes para deslegitimar o regime monárquico e propagar o ideário republicano. No Rio de Janeiro, onde o movimento teve um caráter mais urbano, esteve envolvido com republicanos mais 'radicais'; colaborou no popular Correio do Povo, dirigido por Sampaio Ferraz, no qual dividiu colunas ao lado de Aristides Lobo. Como se autodenominava um socialista recusou uma série de cargos políticos por divergências ideológicas. Teve experiências profissionais variadas e de curta duração: foi funcionário de uma empresa de exportação de produtos paranaenses para a Europa; envolveu-se na criação de uma indústria de papel em Morretes e criou gado nos Campos Gerais. Embora fosse frequente o fenômeno de múltiplas ocupações, as de Manoel Correia de Freitas apontam para uma situação social e uma disponibilidade financeira que o diferenciava dos intelectuais de classe média pois podia dedicar-se à sua preocupação central do ideário republicano que tão cedo o cativara; era mais um propagandista do que um escritor.

Ao pensarmos numa biografia qualquer, automaticamente relacionamos esta palavra com uma narrativa sobre a vida de uma pessoa. E de fato uma biografia não deixa de ser isto, mas existem formas diferenciadas de elaborar este "relato". Inicialmente produzir uma biografia era algo que pertencia ao campo literário, e muitas vezes este exercício era feito de forma romanceada. Num outro momento o historiador se envolveu nesta empreitada, dando um outro caráter a biografia, a qual passou a ter o dever de ser uma história de vida exata, baseada em documentos e com uma descrição inteligível dos fatos referentes à vida de um indivíduo.

Outras formas correlatas de biografia também são vistas nesta seara, tais como a autobiografia, as memórias, os diários e as cartas. Uma biografia pode envolver também a construção de uma imagem apologética em relação ao biografado, e sempre exaltar somente o caráter positivo durante a vida de um sujeito.

Neste contexto, não se pretende elaborar uma biografia nos moldes citados acima, mas sim uma obra individual ou biografia de caráter sociológico. Nessa proposta, ao pensar a história de uma vida, esta pode ser entendida através daquilo que Bourdieu denomina de pensar relacionalmente, ou seja, construir um sistema de relações que deve ser colocado à prova, interrogando sistematicamente casos particulares, com o intento de localizar as propriedades gerais ou invariantes. Logo, não se deve pensar a história de uma vida como um trajeto ou um percurso 
linear e unidirecional com um começo, um meio (onde o biografado sempre obtém sucesso) e um fim; muito menos se deve criar uma história de vida com base em certos acontecimentos significativos justificando sua existência produzindo uma interpretação artificial de sentido, construindo então uma "nova" vida para o biografado. Para encaminhar uma pesquisa nestes moldes com austeridade:

é preciso situar o corpus assim constituído no interior do campo ideológico de que faz parte, [...], é necessário determinar previamente as funções de que se reveste este corpus no sistema das relações de concorrência e de conflito entre grupos situados em posições diferentes no interior de um campo [...] que, por sua vez, também ocupa uma dada posição no campo de poder (BOURDIEU, 1996a, p.186).

Diante desta proposição biográfica verificam-se diversos trabalhos na área da sociologia. Estes abrangem biografados de vários segmentos sociais, tais como literatos, religiosos, artistas, políticos, intelectuais, etc. Outros trabalhos, ainda dentro desta lógica relacional, constroem uma rede de relações que suporta um conjunto de biografados interdependentes. Com o intuito de construir a biografia de Manoel Correia de Freitas de uma perspectiva sociológica, devemos ter sempre em mente que é impossível analisar uma vida como uma série única e auto-suficiente, desmembrada de outros vínculos e ligações, principalmente, como adverte Bourdieu, se considerar somente o nome próprio do sujeito como constante. Devemos estar cientes de que:

Os acontecimentos biográficos definem-se antes como alocações e como deslocamentos no espaço social, isto é, mais precisamente, nos diferentes estados sucessivos da estrutura da distribuição dos diferentes tipos de capital que estão em jogo no campo considerado. [...] não podemos compreender uma trajetória (ou seja, o envelhecimento social que, ainda que inevitavelmente o acompanhe, é independente do envelhecimento biológico), a menos que tenhamos previamente construído os estados sucessivos do campo no qual ela se desenrolou; logo, o conjunto de relações objetivas que vincularam o agente considerado pelo menos em certo numero de estados pertinentes do campo - ao conjunto dos outros agentes envolvidos no mesmo campo e que se defrontaram no mesmo espaço de possíveis. Essa construção prévia é também condição de qualquer avaliação rigorosa do que poderíamos chamar de superfície social, como descrição rigorosa da personalidade designada pelo nome próprio, em um momento dado do tempo, por uma individualidade biológica socialmente instituída, que age como um suporte de um conjunto de atributos e de atribuições que permitem sua intervenção como agente eficiente nos diferentes campos. (BOURDIEU, 1996a, p. 182)

Neste projeto, para construir a biografia e iluminar a relação entre Manoel Correia de Freitas, seu habitus, e as forças de um campo o faremos por meio da construção da trajetória deste 
agente singular. Deste modo nos apropriaremos do conceito bourdiesiano de trajetória social significado como "[...] a série das posições sucessivamente ocupadas por um mesmo agente ou por um mesmo grupo de agentes em espaços sucessivos do campo.” (BOURDIEU, 1996b, p. 292).

Nos estudos anteriores sobre o republicanismo e a propaganda antimonárquica no Brasil, Manoel Correia sempre é citado e considerado um personagem importante para o movimento republicano no Brasil, porém percebe-se uma lacuna na discussão sobre a sua trajetória social. Um autor acaba citando o outro e nenhum dos trabalhos existentes procurou entender as condições sociais, políticas e intelectuais que caracterizam a trajetória de Manoel Correia. A relevância de efetuar uma pesquisa acerca da trajetória de vida desse um indivíduo se dá por dois fatores. O primeiro consiste na carência de pesquisas no âmbito da política paranaense. O segundo diz respeito ao fato de que Manoel Correia interfere e participa das decisões praticadas na esfera política do período estudado, desse modo influencia e é influenciado em todo período de sua atuação. Dessa forma se buscará compreender as diversas relações, o habitus e os campos em questão de forma objetiva, atualizando a história em consequência do habitus, como "produto de uma aquisição histórica que permite a apropriação do adquirido histórico" (BOURDIEU, 2002, p.83), refletindo sempre acerca de dois estados da história, ou do social, a "história no seu estado objectivado, quer dizer, a história que se acumulou ao longo do tempo nas coisas, máquinas, edifícios, monumentos, livros, teorias, costumes, direito, etc., e a história no seu estado incorporado, que se tornou habitus.” (BOURDIEU, 2002, p.82)

A reconstituição da trajetória social do biografado procura os mecanismos responsáveis pela sua ascensão social no campo político, assim como as marcas positivas e negativas de sua vida pessoal e pública. Para isso, estaremos baseados nos conceitos de campo e de habitus, com o intuito de analisar a dinâmica dessa trajetória e compreender, através da aplicação desses conceitos, como ocorre sua inserção e sua circulação no interior dos campos.

Os objetivos específicos consistirão em mostrar como se deu a presença do político em algumas instituições importantes dentro de uma esfera do poder local no período em que viveu, tentando compreender como o personagem em questão se relacionava com as pessoas que também viveram no mesmo período. Ao mesmo tempo é necessário entender em que medida estas influenciaram ou ocasionaram certas tomadas de posições no espaço social ao longo de sua trajetória. 


\section{REFERÊNCIAS}

BOURDIEU, Pierre. (1968) "Campo intelectual e projeto criador". IN: POUILLON, Jean (org). Problemas do estruturalismo. RJ: Zahar, pp.105-145. . (2004). A economia das trocas simbólicas. 5 ed., São Paulo: Perspectiva.

. (1996a). "A ilusão biográfica”. IN: FERREIRA, Marieta de Morais e AMADO, Janaína (orgs). Usos e abusos da história oral. RJ: Fundação Getúlio Vargas, pp 183-191.

. (1996b). Razões práticas: sobre a teoria da ação. Campinas: Editora Papirus.

. (2002). "A representação política. Elementos para uma teoria do campo político". IN: O

poder simbólico. RJ: Bertrand do Brasil, pp.163-207. 